\title{
A disappearing act in the pituitary fossa with recovery from hypopituitarism
}

E Goodchild ${ }^{1}$, J Evanson², WM Drake ${ }^{1}$, N Glynn ${ }^{1}$.

Departments of Endocrinology ${ }^{1}$ and Radiology², St Bartholomew's Hospital, London

A 36-year-old, previously healthy, gentleman presented with several weeks' history of gradually worsening frontal headache. He attended the Emergency Department after he was awoken by sudden worsening of the headache, associated with vomiting and pre-syncopal symptoms. He did not report any visual problems.

On further questioning, he described decreased libido for several weeks. On examination, he was alert and orientated, hypothermic at $35.1^{\circ} \mathrm{C}$ and bradycardic - 55bpm. He had no evidence of meningeal irritation but examination of vision revealed an right upper, lateral quadrantanopia.

Investigations:

- Severe hyponatraemia with a serum sodium $109 \mathrm{mmol} / \mathrm{L}$. He was also profoundly hypocortisolaemic with a random serum cortisol of $16 \mathrm{nmol} / \mathrm{L}$

- $\mathrm{CT}$ head, and later MRI, pituitary demonstrated a $17 \mathrm{~mm}$ suprasellar, complex, cystic pituitary lesion compressing the optic apparatus (panel A); there was no calcification within the mass on CT (not shown).

\begin{tabular}{ll} 
& Baseline \\
\hline Free T4 (pmol/L) & $\mathbf{6 . 1}$ \\
\hline TSH (mUnit/L) & $\mathbf{0 . 6 8}$ \\
Cortisol (nmol/L) & $\mathbf{1 6}$ \\
ACTH & $\mathbf{1 9}$ \\
\hline Prolactin (0 -324 mUnit/L) & 101 \\
\hline Testosterone (8-29 nmol/L) & $\mathbf{0 . 8}$ \\
\hline SHBG (nmol/L) & $\mathbf{3 8}$ \\
\hline $\begin{array}{l}\text { Insulin-like growth factor } \\
\text { ref. range 99-367(mcg/L) }\end{array}$ & $\mathbf{9 4}$ \\
\hline
\end{tabular}

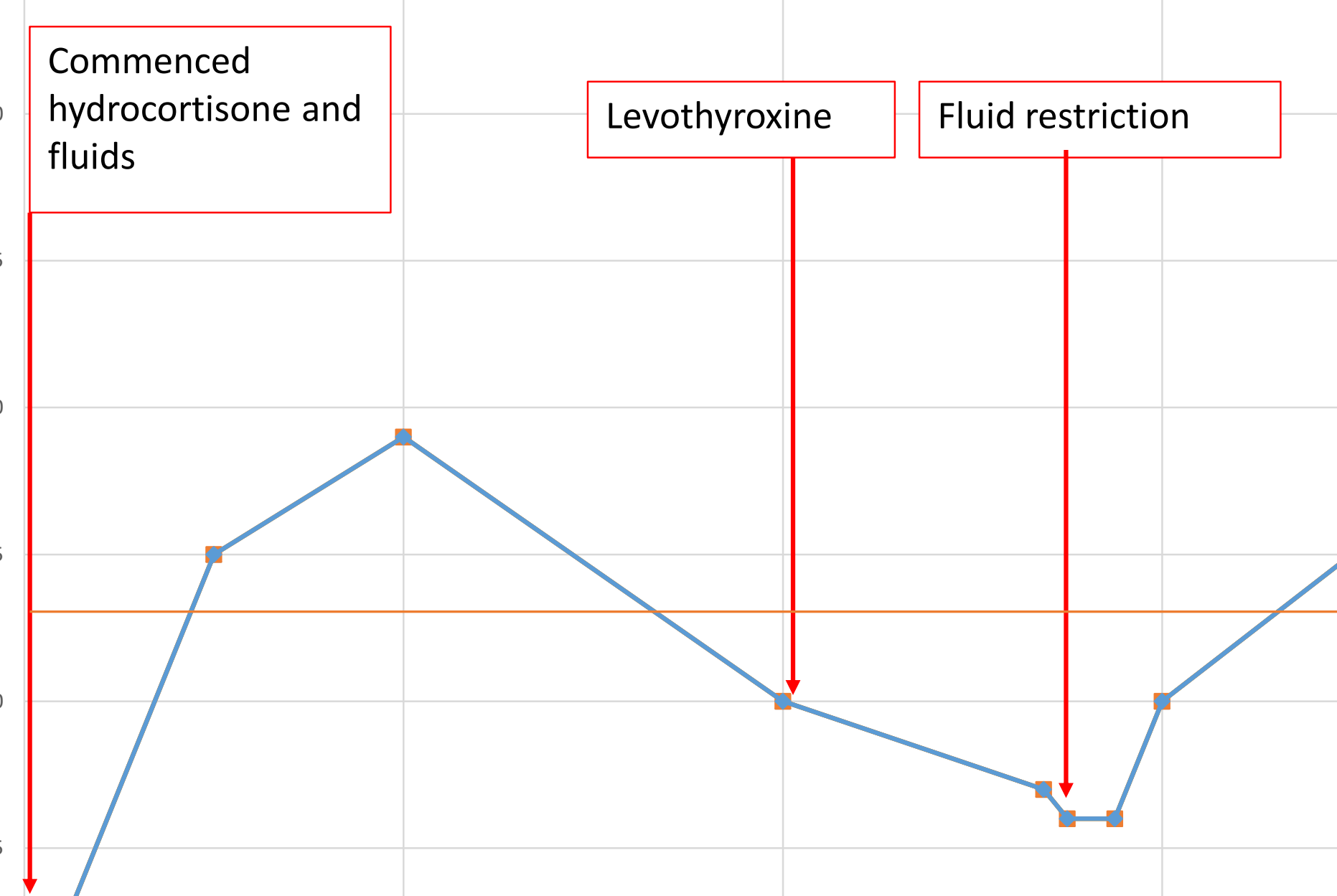

Panel A

Figure 2 Serial pituitary MRI scans. Panel A:

Presentation- Enlarged pituitary fossa containing

a $17 \mathrm{~mm}$ cystic mass lesion, suprasellar

extension deforming the chiasm. Enhancement of the cyst wall and stalk appears foreshortened. Panel B: 6 weeks - Cystic tissue is completely within the sella and significantly reduced in size with no chiasm compression. Panel C: 6 monthsNormal volume of pituitary tissue which is of diffuse T1 high signal suggesting proteinaceous or old haemorrhagic content. Optic chiasm is normal and stalk midline.
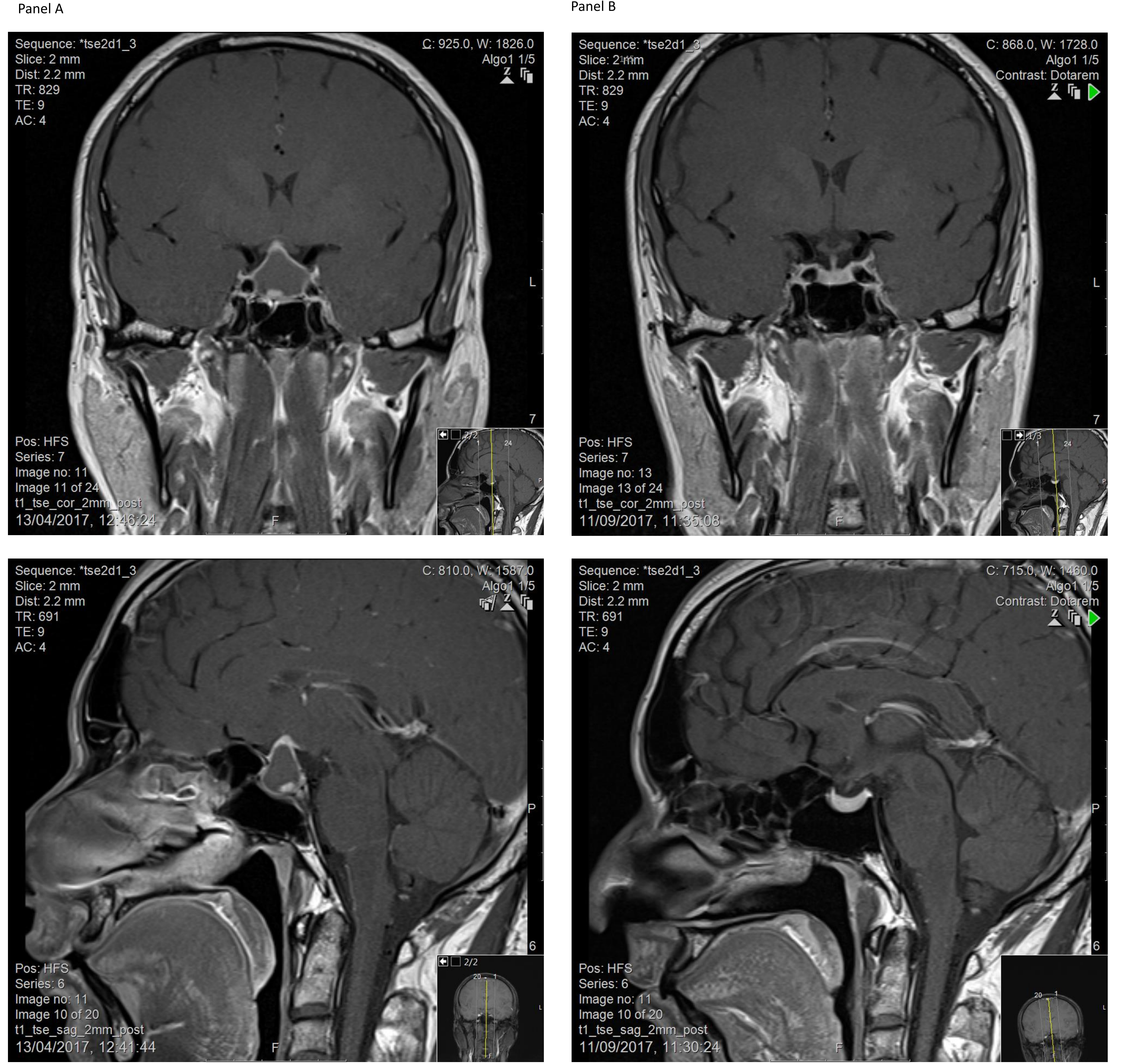

Management: Treated with IV 0.9\% saline and glucocorticoids. Serum $\mathrm{Na}$ initially improved to $129 \mathrm{mmol} / \mathrm{L}$ and he felt better. However, after 4 days, he complained of headache with nausea - serum sodium declined again (Figure 1) Clinically euvolaemic and repeat biochemical assessment confirmed a persistent state of antidiuresis despite replacement of glucocorticoids - serum sodium 116, urine osmolality $726 \mathrm{mOsm} / \mathrm{kg}$, urine $\mathrm{Na} 62 \mathrm{mmol} / \mathrm{L}$. He was then treated with fluid restriction, while continuing glucocorticoids and T4, and serum sodium gradually returned to the normal range.

Progress: He had panhypopituitarism, without polyuria (table 1). Serum prolactin was not elevated, so the neurosurgical team planned transsphenoidal debulking; however, repeat pituitary imaging, six weeks later, demonstrated substantial shrinkage of the lesion, now confined to the sella (panel B).

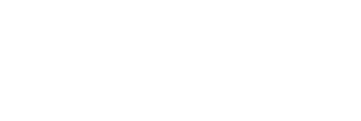

